\title{
Effects of age and parity on litter size and offspring sex ratio in golden hamsters (Mesocricetus auratus)
}

\author{
U. W. Huck, N. C. Pratt*, J. B. Labov† and R. D. Lisk* \\ Biology Program, Sangamon State University, Springfield, IL 62708, U.S.A.; \\ * Department of Biology, Princeton University, Princeton, NJ 08544, U.S.A.; and \\ $\dagger$ Department of Biology, Colby College, Waterville, ME 04901, U.S.A.
}

\begin{abstract}
Summary. Golden hamsters that were mated repeatedly from 55 days of age produced 6-12 litters. Litter size at birth rose between the 1 st and 2 nd litters, peaked on the 3rd, and declined steadily after the 5 th litter. Offspring sex ratio (\% male) at birth followed a similar pattern: increasing between the 1 st and 2 nd litters, remaining high through the 3 rd, and becoming increasingly female-biased thereafter. Weaning success decreased sharply after the 6 th litter and most dams failed to raise any young to weaning after the 9 th litter. These sequential effects on litter size, offspring sex ratio and weaning success were also observed in females mated once at different ages, but they occurred considerably later in life, i.e. increasing parity hastened the effects of advanced age. These ageand parity-related changes in litter composition are consistent with the Trivers-Willard hypothesis that physiologically-stressed females would skew offspring sex ratios to favour daughters. However, since the observed changes in sex ratio were probably due to differential prenatal mortality, their adaptive significance is unclear.
\end{abstract}

Keywords: age; parity; sex ratio; weaning success; golden hamsters; litter size

\section{Introduction}

Reproduction requires mobilization of extensive energy resources in placental mammals. Consecutive pregnancies are likely to be stressful, impairing the physiological condition of the female (e.g. Clutton-Brock \& Albon, 1982), which, in turn, may be reflected in litter size at birth, offspring sex ratio (percentage male), and/or weaning success. Although demographic studies on humans indicate a significant negative correlation between birth order and offspring sex ratio (Garfinkel \& Selvin, 1976; Imaizuma \& Muraka, 1979; James, 1979), few studies of non-human mammals that relate the sex ratio at birth to maternal lifetime parity demonstrate significant trends (Clutton-Brock \& Iason, 1986).

Another stressor that may affect offspring sex ratio is maternal age. In several human populations, sex ratio has been shown to decline with maternal (and paternal) age after the effects of parity have been statistically removed (Garfinkel \& Selvin, 1976; James \& Rostron, 1985), although these effects were small. In other mammals, the effects of age are variable, with some species showing a tendency for the sex ratio to decline with maternal age, others showing a tendency for it to increase, and still others showing no obvious tendency at all (Clutton-Brock \& Iason, 1986). However, it is difficult to separate the effects of age from those of parity in natural populations.

In species in which there is little or no paternal care in producing or rearing young, the quality of parental investment offspring receive will be dependent in part on the physical condition of the mother during the period of investment. Trivers \& Willard (1973) reasoned that, if variance in reproductive success is greater in one sex than in the other, females in good physiological condition should produce an offspring sex ratio which favours the sex of greater variance, since it is that 
sex which will benefit more from parental investment. In polygynous and promiscuous species, in which maternal condition affects offspring condition, males usually have a greater variance in reproductive success (e.g. Daly \& Wilson, 1983). Therefore, females in good condition should produce proportionately more male offspring than females in poor condition. Several investigators have tested the Trivers-Willard hypothesis by using food-restriction (Verme, 1969; Rivers \& Crawford, 1974; Labov et al., 1986; Meikle \& Drickamer, 1986) or social subordination (Altmann, 1980; Clutton-Brock et al., 1981; Simpson \& Simpson, 1982; Silk, 1983; Meikle et al., 1984; Paul \& Thommen, 1984) as stressors, yet little attempt has been made to investigate the effects of increasing age and parity on offspring sex ratio in an animal model.

The present study was designed to determine whether litter size and offspring sex ratio changed as a function of consecutive matings in the golden hamster and, if so, to clarify the relative effects of maternal age and parity. The latter objective was accomplished by comparing the composition of successive litters born to females mated repeatedly throughout their lives to that of groups of females mated once during their lifetime at different ages.

\section{Materials and Methods}

Subjects were 307 laboratory-born descendants of the randomly mated LVG strain of hamsters (Mesocricetus auratus) obtained from Charles River, Inc. All subjects were maintained on a $14 \mathrm{~h}$ light (22:00-12:00): $10 \mathrm{~h}$ dark photoperiod in humidity- and temperature-controlled rooms, and were provided with rodent chow and water ad libitum.

Thirty-six females were mated to satiety at $13: 00 \mathrm{~h}$ ( $1 \mathrm{~h}$ after lights-off) with proven stud males at $55 \pm 2$ days of age and placed into plastic breeding boxes $(38 \times 30 \times 17 \mathrm{~cm})$ with wood shavings. Litter size (number of young per litter) and the sex of each offspring (determined by examination of ano-genital distance) were recorded at parturition and 25 days later. Weaning success was determined by dividing the number of young alive at 25 days by the number present at parturition. These females were mated repeatedly at 45-50 day intervals until the dams died, and litter size, sex ratio and weaning success were recorded for each litter. The remaining 271 subjects were randomly assigned to one of 11 groups $(\mathrm{N}=20-38$ per group) and mated once each at various times between 55 and 500 days of age (see Fig. 1). The ages at which these groups of females were mated corresponded to the ages at which repeatedly-mated females were mated.

Effects of repeated mating and age at first mating on litter size, offspring sex ratio, and weaning success were initially analysed using analysis of variance (ANOVA) tests. Neuman-Keuls multiple range comparison tests (corrected for unequal sample sizes) were used to test further for differences between two categories. Comparisons between repeatedlymated females and females mated once at corresponding ages were made by Wilcoxon signed-ranks tests. Paired $t$ tests were used to determine whether offspring sex ratios differed significantly from unity.

\section{Results}

\section{Effects of repeated mating}

Females mated repeatedly, beginning at 55 days of age, produced 6-12 litters (mean = $9 \cdot 1 \pm 0 \cdot 3)$. ANOVA tests indicated significant $(P<0.001)$ changes in litter size, offspring sex ratio and weaning success among consecutive litters. Neuman-Keuls tests further indicated that litter size at parturition increased significantly $(P<0.05)$ between the 1 st and 2 nd litters, remained uniformly high (12-14 young) through the 5th litter, declined sharply by the 6 th litter $(P<0.01)$ and dropped steadily thereafter (Fig. 1a). Offspring sex ratio at parturition followed a similar pattern: i.e. increasing between the 1 st $(42 \%$ male) and 2 nd $(50 \%)$ litter $(P<0.05)$, remaining relatively high through the $3 \mathrm{rd}(47 \%)$ and becoming increasingly female-biased thereafter $(40 \%$ in the 5 th and $29 \%$ in the 10th) (Fig. 1b). Paired $t$ tests indicated that daughters significantly outnumbered sons in all but the 2 nd and 3 rd litters $(P<0.05)$. Weaning success tended to increase from the 1 st $(72 \%)$ to the 2 nd $(79 \%)$ litter $(P<0.09)$ and decreased steadily and significantly thereafter (Fig. 1c). Few repeatedly-mated dams raised any young to weaning after their 9 th litter (Table 1). There were no appreciable changes in offspring sex ratio between parturition and weaning. 



Litter number for females mated repeatedly

(age (days) when mated for females mating once)

Fig. 1. Mean ( \pm s.e.m.) litter size (a), litter sex ratio (b) and proportion of young alive at 25 days of age (c) in repeatedly-mated and once-mated female hamsters. *Significant differences between the groups of females. 
Table 1. Delivery rates and weaning success of golden hamsters mated repeatedly or only once

\begin{tabular}{|c|c|c|c|c|c|c|}
\hline \multirow{2}{*}{$\begin{array}{l}\text { Age when } \\
\text { mated } \\
\text { (in days) }\end{array}$} & \multicolumn{2}{|c|}{ No. mated } & \multicolumn{2}{|c|}{ No. delivering $(\%)$} & \multicolumn{2}{|c|}{ No. weaning $(\%)$} \\
\hline & Repeatedly & Once & Repeatedly & Once & Repeatedly & Once \\
\hline 55 & 36 & 36 & $36(100)$ & $36(100)$ & $36(100)$ & $36(100)$ \\
\hline 100 & 36 & 36 & $36(100)$ & $36(100)$ & $36(100)$ & $36(100)$ \\
\hline 150 & 36 & 20 & $36(100)$ & $20(100)$ & $32(89)$ & $20(100)$ \\
\hline 195 & 36 & 21 & $36(100)$ & $21(100)$ & $29(81)$ & $21(100)$ \\
\hline 240 & 36 & 38 & $36(100)$ & $38(100)$ & $28(78)$ & *38 (100) \\
\hline 285 & 36 & 20 & $36(100)$ & $20(100)$ & $29(81)$ & $20(100)$ \\
\hline 325 & 35 & 20 & $35(100)$ & $20(100)$ & $19(54)$ & $* 20(100)$ \\
\hline 365 & 33 & 20 & $29(88)$ & $20(100)$ & $16(55)$ & $* 20(100)$ \\
\hline 410 & 33 & 20 & $23(70)$ & $17(85)$ & $6(26)$ & *15 (88) \\
\hline 455 & 32 & 20 & 14 (44) & $11 \quad(55)$ & $4(29)$ & $5(45)$ \\
\hline 500 & 31 & 20 & 7 (23) & $8 \quad(40)$ & 0 & $2(25)$ \\
\hline 545 & 30 & & $2(7)$ & & 0 & \\
\hline
\end{tabular}

$* P<0.05$ compared with females mated repeatedly.

\section{Effects of age in females mated once}

There were significant effects of maternal age on litter size, sex ratio and weaning success (ANOVA tests, $P<0.001$ ) among females mated once but at different ages. Both litter size and sex ratio were significantly higher for females mated for the first time at 100 days than at age 55 $(P<0.01)$. Weaning success showed a similar, non-significant trend $(P<0.09)$. Litter size, offspring sex ratio and weaning success remained uniformly high among females mated between 100 and 285 days of age (Fig. 1). However, litter size, sex ratio and weaning success were all significantly reduced $(P<0.05)$ among females mated at 325 days or thereafter. Significant further declines in litter size, offspring sex ratio and weaning success occurred in females mated at more advanced ages. Sons significantly outnumbered daughters in litters of females mated at 150-285 days of age (paired $t$ tests, $P<0.05$ ) whereas daughters outnumbered sons in litters of females mated at 55, 455 or 500 days $(P<0.01)$. As in the case of females mated repeatedly, there were no significant differences in offspring sex ratio between parturition and weaning.

\section{Repeated mating versus one-time mating}

In general, the sequential effects on litter size, offspring sex ratio and weaning success observed in dams mated repeatedly were also observed in females mated only once, but not until a later age. Specifically, litter sizes were significantly lower (Wilcoxon signed-ranks tests, $P<0.05$ ) for repeated breeders producing their 6th through 9th litters than for females mated once at each corresponding age (Fig. 1a). Similarly, offspring sex ratios were significantly lower $(P<0.05)$ for females repeatedly mated producing their 3rd through 10 th litters than for females mated once (Fig. 1b). The number of females successfully weaning at least some young (Table 1) as well as the percentage of offspring weaned (Fig. 1c) showed a similar pattern. By 500 days of age, however, there were no significant differences in the size or composition of litters produced by females mated for the first time and those producing their 11 th consecutive litter.

\section{Discussion}

The data presented here are consistent with the Trivers-Willard hypothesis: females which are physiologically stressed (breeding very young, very old, or very often) produced litters with significantly lower sex ratios than did those in peak condition. Williams (1979) and Clutton-Brock \& 
Iason (1986) argued that in most large mammals maternal condition is at its peak during some intermediate age since females usually begin breeding before they have reached their full body weight and repeated breeding causes a decline in maternal condition by old age. A similar relationship between age and maternal condition probably exists for small mammals as well. Not surprisingly, litter size varies with age (and therefore parity) in most polytocous species with the largest litter produced during some intermediate age (Williams, 1979). Applying these findings to the present study, it seems reasonable to predict that litter sex ratios would be lower among young, first-breeders and older, multiparous animals than among females in peak condition during an intermediate age. Indeed, the results of this study show that sex ratio increases between the 1 st and 2 nd litters, remains high through the 5 th litter and then drops sharply thereafter in females mated repeatedly.

In an ill-defined sample of 81 pregnant golden hamsters, sex ratio immediately before implantation was reported as $64.3 \%$ but because of differential prenatal mortality, the ratio at parturition was found to be $50 \cdot 3 \%$ (Sundell, 1962). Reduced survival of male embryos appears to be a common feature of mammalian reproduction (e.g. McMillen, 1979; Clutton-Brock \& Albon, 1982; Trivers, 1985; Clutton-Brock \& Iason, 1986) and may account for some of the results obtained in the present study. The lower sex ratios noted in repeatedly-mated females and in older, once-mated females were the result of a decrease in the number of male young, rather than of an increase in the number of daughters. Reduced sex ratios at birh, matched by a corresponding reduction in litter size, has been documented in house mice (Rivers \& Crawford, 1974; Meikle \& Drickamer, 1986) and golden hamsters (Labov et al., 1986) subjected to restricted diets during gestation. Hamsters socially subordinated before implantation or late in gestation also produced smaller, female-biased litters (N. C. Pratt, U. W. Huck \& R. D. Lisk, unpublished data). Therefore, it appears that the differential vulnerability of males in utero is exacerbated by various forms of maternal stress. The physiological mechanism by which this occurs, however, is unknown at this time.

The adaptive advantage of sex ratio modification by means of differential prenatal mortality of one sex is unclear since it can only come about by a reduction in litter size (e.g. Myers, 1978). McGinley (1984) proposed that by reducing litter size, a mother could divert additional investment toward fewer progeny. Therefore, stressed females with smaller litters could still contribute as much parental investment toward surviving sons than could non-stressed females with larger litters. Although this hypothesis may hold for species with small litter sizes (see McGinley, 1984), the present data do not support it. As discussed above, the smaller litters in this study tended to be female-biased.

The Trivers-Willard model does not restrict sex ratio modification to a prenatal mechanism; mothers can also alter the sex ratios of offspring after birth. McClure (1981) found that, when wood rats were deprived of food during lactation, they would reduce sex ratios by selectively neglecting male young. However, in the present study, we found no evidence for post-natal sex ratio adjustment; there were no significant differences in sex ratio between birth and weaning in either group. Also, no post-natal sex ratio modification occurred in our previous work with this species (Huck et al., 1986; Labov et al., 1986). This finding was not unexpected in view of the high cost of infanticide as a post-natal mechanism for sex ratio adjustment (see Burley, 1982; Labov et al., 1985).

Although increasing age and parity produced similar changes in litter size, offspring sex ratio, and weaning success, increasing parity significantly hastened the detrimental effects of advanced age at mating. The effects of repeated mating on reproductive success were more extreme than those of ageing. The reason(s) for the decline in fecundity with increasing age and parity are not entirely clear. Gosden (1974) found that only $7 \%$ of embryos obtained from the uteri of young (2-4 months old) donor mice survived to Day 19 when transplanted into the uteri of old (10-16 months old) hosts, whereas $38 \%$ survived in young hosts. Furthermore, embryos from old mice survived as well as those from young mice when transplanted into young hosts. In contrast, in golden hamsters, normal ova transferred from the uteri of old to young hosts rarely survived to term (Blaha, 1964). Although additional studies are warranted, it is possible that both effects (impaired viability of ova and unfavourable uterine environment) occur, but that their relative 
importance varies with increasing maternal age or parity. Future studies should seek to establish the numbers of embryos and sex ratios at implantation among females of various ages and parity, in order to identify the mechanism by which sex ratio is modified in utero.

This research was supported by National Science Foundation Grant BNS-8607258 and by the Biology Department of Princeton University.

\section{References}

Altmann, J. (1980) Baboon Mothers and Infants. Harvard University Press Cambridge.

Blaha, G.C. (1964) Effect of age of the donor and recipient on the development of transferred golden hamster ova. Anat. Rec. 150, 413-416.

Burley, N. (1982) Facultative sex-ratio manipulation. Am. Nat. 120, 81-107.

Clutton-Brock, T.H. \& Albon, S.E. (1982) Parental investment in male and female offspring in mammals. In Current Problems in Sociobiology, pp. 223-247. Cambridge University Press, Cambridge.

Clutton-Brock, T.H. \& Iason, G.R. (1986) Sex ratio in mammals. Quart. Rev. Biol. 61, 339-374.

Clutton-Brock, T.H., Albon, S.E. \& Guinness, F.E. (1981) Parental investment in male and female offspring in polygynous mammals. Nature, Lond. 289, 487-489.

Daly, M. \& Wilson, M. (1983) Sex, Evolution, and Behaviour, 2nd edn. Willard Grant Press, Boston.

Garfinkel, J. \& Selvin, S. (1976) A multivariate analysis of the relationship between parental age and birth order and the human secondary sex ratio. J. biosoc. Sci. 8, 113-121.

Gosden, R.G. (1974) Survival of transferred C57B! mouse embryos: effects of age of donor and recipient. Fert. Steril. 25, 348-351.

Huck, U.W., Labov, J.B. \& Lisk, R.D. (1986) Food restricting young hamsters (Mesocricetus auratus) affects sex ratio and growth of subsequent offspring. Biol. Reprod. 35, 592-598.

Imaizuma, Y. \& Muraka, M. (1979) The secondary sex ratio, paternal age, and birth order in Japan. Ann. Hum. Genet. 42, 457-465.

James, W.H. (1979) Is Weinberg's differential rate valid? Acta Genet. Med. Geo. 28, 69-71.

James, W.H. \& Rostron, J. (1985) Parental age, parity, and sex ratio in births in England and Wales 1968-1977. J. biosoc. Sci. 17, 47-56.

Labov, J.B., Huck, U.W., Elwood, R.W. \& Brooks, R.J. (1985) Current problems in the study of infanticidal behaviour of rodents. Quart. Rev. Biol. 60, 1-20.

Labov, J.B., Huck, U.W., Vaswani, P. \& Lisk, R.D. (1986) Sex ratio manipulation and decreased growth of male offspring of undernourished golden hamsters (Mesocricetus auratus). Beh. Ecol. Sociobiol. 18, $241-249$.

McClure, P.A. (1981) Sex biased litter reduction in food-restricted wood rats (Neotama floridana). Science, N.Y. 211, 1058-1060.
McGinley, M.A. (1984) The adaptive value of malebiased sex ratios among stressed animals. Am. Nat. 124, 597-599.

McMillen, M.M. (1979) Differential mortality by sex in fetal and neonatal deaths. Science, N.Y. 204, 89-91.

Meikle, D.B. \& Drickamer, L.C. (1986) Food availability and secondary sex ratio variation in wild and laboratory house mice (Mus musculus). J. Reprod. Fert. 78, 587-591.

Meikle, D.B., Tilford, B.L. \& Vessey, S.H. (1984) Dominance rank, secondary sex ratio, and reproduction of offspring in polygynous primates. $A \mathrm{~m}$. Nat. 124, 597-599.

Myers, J.H. (1978) Sex ratio adjustment under food stress: maximization of quality or numbers of offspring? Am. Nat. 112, 381-388.

Paul, A., \& Thommen, D. (1984) Timing of birth, female reproductive success and infant sex ratio in semi-freeranging Barbary macaques (Macaca sylvanus). Folia Primatol. 42, 2-16.

Rivers, J.P.W. \& Crawford, M.A. (1974) Maternal nutrition and sex ratio at birth. Nature, Lond. 252 , 297-298.

Silk, J.B. (1983) Local resource competition and facultative adjustment of sex ratios in relation to competitive abilities. Am. Nat. 121, 56-66.

Simpson, M.J.A. \& Simpson, A.E. (1982) Birth sex ratios and social rank in rhesus monkey mothers. Nature, Lond. 300, 440-441.

Sundell, G. (1962) The sex ratio before uterine implantation in the golden hamster. J. Embryol. exp. Morph. 10, 58-63.

Trivers, R.L. (1985) Social Evolution. Benjamin Cummings Publishing Company, Inc., Menlo Park.

Trivers, R.L. \& Willard, D.E. (1973) Natural selection of parental ability to vary the sex ratio of offspring. Science, N.Y. 179, 90-92.

Verme, L.J. (1969) Reproductive patterns of white-tailed deer related to nutritional plane. J. Wildl. Manage. 33, 881-887.

Williams, G.C. (1979) The question of adaptive sex ratios in outcrossed vertebrates. Proc. $R$. Soc. Lond. B. 205, $567-580$. 